\title{
FORMULATION OF CINNAMON BARK ESSENTIAL OIL GEL AS MOSQUITO REPELLENT
}

\author{
DHADHANG WAHYU KURNIAWAN ${ }^{*}$, VIDYA NUR AGUSTINA ${ }^{1}$, SUNART0 ${ }^{1}$, GUNAWAN ADI WIBOWOㄹ, \\ MUHAMMAD ZAENURI SYAMSU HIDAYAT ${ }^{2}$
}

${ }^{1}$ Department of Pharmacy, Faculty of Health Sciences, Universitas Jenderal Soedirman, Jl. Dr. Suparno Kampus Unsoed Karangwangkal Purwokerto, Central Java, 53123, Indonesia, ${ }^{2}$ Faculty of Medicine, Universitas Jenderal Soedirman, Jl. Dr. Gumbreg No 1 Mersi

Purwokerto, Central Java, Indonesia

*Email: dhadhang.kurniawan@unsoed.ac.id

Received: 02 Sep 2021, Revised and Accepted: 18 Oct 2021

\section{ABSTRACT}

Objective: The purpose of this research is to prepare a cinnamon bark essential oil gel preparation, determines the physical characteristic and physical stability during storage, and examines the activity of mosquito repellent from the best gel preparation.

Methods: The formulations of gel were made with variations in the concentration of Carbopol 940 (0.5\%, 1.5\%, and 2\%) contain 1\% of cinnamon bark essential oil. The gel evaluated physical characteristics and physical stability. The parameters of organoleptic, homogeneity, and pH are analyzed descriptive, while the viscosity, the spreadability, and the gel adhesion were analyzed using one-way ANOVA at the level of confidence of 95\%. The best gel tested its effectiveness as compared to the negative control and product innovator (which used DEET as an active compound) as a positive control. The activity of repellent was determined by an Aedes aegypti mosquito for 6 h with 2 hands respondents. The effectiveness of repellent protection is calculated by the percentage of protection power.

Results: The studies showed that all the gel preparations qualified the organoleptic, homogeneity, and pH parameters. The viscosity, gel adhesion, and spreadability are also stable during storage.

Conclusion: Based on the results, the best gel is the formula I which has mosquito repellent activity effective for $6 \mathrm{~h}$ like DEET.

Keywords: Cinnamon (C. burmanii) bark, Essential oil, Gel formulation, Repellent, DEET

(c) 2022 The Authors. Published by Innovare Academic Sciences Pvt Ltd. This is an open access article under the CC BY license (https://creativecommons.org/licenses/by/4.0/) DOI: https://dx.doi.org/10.22159/ijap.2022v14i1.43034. Journal homepage: https://innovareacademics.in/journals/index.php/ijap

\section{INTRODUCTION}

Indonesia is a tropical country rich in various types of insects that provide benefits, but some are detrimental [1]. One of the insect groups that harm humans is mosquitoes which are vectors of various diseases, including malaria, dengue hemorrhagic fever (DHF), and chikungunya [2]. To prevent mosquito bites, some efforts are applied such as by using mosquito repellent sprays (spray), mosquito coils (coil), and repellent preparations are generally used [3].

Repellents had been marketed at this time are repellent made of chemical containing the active ingredient $\mathrm{N}, \mathrm{N}$-dietil-m-toluamid (DEET) [4]. DEET has good repellency because it can provide a period of protection ranging from 2 to $8 \mathrm{~h}$ depending on the concentration in the product [5]. However, the use of DEET potentiates endanger health by having various side effects such as hypersensitivity, irritation, and urticaria and in the long term use can cause cancer [6].

Therefore, to avoid the occurrence of dangers due to the usage of DEET on health, an alternative natural mosquito repellent preparation made from natural ingredients is needed to replace DEET. One of the plants that are known to be effective as mosquito repellent is the cinnamon plant [7]; Cinnamomum genus well known has many biological activities [8]. Cinnamon bark essential oil contains eugenol $(17,62 \%)$, which is able to resist the bite of Aedes aegypti and Anopheles mosquitoes [9]. The mechanism of this process is not known for certain, but eugenol has a pungent odor and a very spicy and hot taste; thus the mosquitoes do not like it [10].

The use of essential oil as a direct repellent is less effective because of the volatile property of essential oil, causing discomfort since they are sticky and give an impression of being warm to hot; hence the selection of dosage forms must be considered [11]. Cinnamon bark essential oil will be easier to use if it is made in pharmaceutical preparation such as gels [12]. Gels have soothing, moisturizing, easy to use, easily penetrated into the skin, thus providing a healing effect [13].

Based on that description, it is necessary to develop the formulation of cinnamon bark essential oil gel preparation and evaluate the effectiveness of cinnamon bark essential oil gel preparations.

\section{MATERIALS AND METHODS}

Instruments and materials

The instruments used in this research include glassware, digital balance, stir bar, watch glass, $\mathrm{pH}$ meter, Brookfield viscometer, measuring pipette, and volume pipette.

The materials used in this study were the main materials, namely cinnamon bark essential oil obtained from Lansida Group, Yogyakarta, Indonesia. The chemicals used in these experiments were carbopol 940, propylene glycol, methylparaben, propylparaben, triethanolamine, aquadest, aluminum foil, and a mosquito repellent product $X$ produced by PT. Johnson as a comparison. The experimental animal used was a four-day-old female Aedes aegypti mosquito, which was obtained from the Laboratory of Parasitology Universitas Gadjah Mada Yogyakarta.

\section{Methods}

Formulation of cinnamon bark essential oil gel

Formulation of the Cinnamon bark essential oil gel for the experiments could be seen in table 1 .

\section{Identification and verification of Cinnamon bark essential oil}

Identification and verification of cinnamon bark essential oil are performed by checking the correctness of the data listed on the certificate of analysis of Cinnamon bark essential oil from Lansida Group Yogyakarta Indonesia. 
Table 1: Cinnamon bark gel formulations

\begin{tabular}{|c|c|c|c|}
\hline \multirow[t]{2}{*}{ Gels composition } & \multicolumn{3}{|c|}{ Formula $(\% \mathrm{w} / \mathrm{v})$} \\
\hline & F1 & F2 & F3 \\
\hline Cinnamon bark essential oil & 1 & 1 & 1 \\
\hline Carbopol 940 & 0,5 & 1,25 & 2 \\
\hline Triethanolamine & 0,75 & 1,875 & 3 \\
\hline Methylparaben & 0,18 & 0,18 & 0,18 \\
\hline Propylparaben & 0,02 & 0,02 & 0,02 \\
\hline Propylene glycol & 10 & 10 & 10 \\
\hline Aquadest & ad 100 & ad 100 & ad 100 \\
\hline
\end{tabular}

\section{Procedure of preparing Cinnamon bark gel}

The gel was prepared by swelling carbopol 940 with distilled water $\left(70^{\circ} \mathrm{C}\right)$ for $24 \mathrm{~h}$ until a homogeneous mass was formed. After cooling and forming a homogeneous mass, methylparaben, propylparaben, and propylene glycol were added until well mixed, then Cinnamon bark essential oil was added and add water to a volume of $100 \mathrm{ml}$ and add triethanolamine dropwise while stirring slowly until a clear gel is formed [14].

\section{Physical stability testing}

The physical stability test in this research was conducted for $4 \mathrm{w}$. The parameters of stability testing observed were homogeneity, $\mathrm{pH}$, organoleptic, viscosity, gel spreadability, and gel adhesion.

To determine the spreadability of Cinnamon bark essential oil gel, we weighed $1 \mathrm{~g}$ of the gel and placed it at the center of the glass slide of standard dimensions $(20 \times 20 \mathrm{~cm})$. The second glass slide was then placed over the first one, on which the gel was put on. A weight of $0.5 \mathrm{~kg}$ was allowed to place on the center of the upper glass slide for $5 \mathrm{~min}$. The diameter of gel was measured in $\mathrm{cm}$ for triplicate to have the mean value [15].

For the first week, these parameters were observed on day 1 to day 7 , continued the second week until the fourth, the evaluation is carried out once a week with 4 repetitions.

\section{Mosquito repellent activity}

The mosquito repellent activity test was performed after receiving a certificate no. 265/EP-FKIK-UMY/VI/2015 about ethical eligibility. The mosquito repellent activity test of Cinnamon bark essential oil gel was carried out by preparing mosquitoes to be grouped randomly into 2 cages made of mosquito nets in the form of blocks, each cage contains 25 mosquitoes. The mosquitoes used were female Aedes aegypti at the age of 3-5 d and before testing, the mosquitoes fasted for $1 \mathrm{~d}$. The mosquito repellent activity was tested using the respondent hands which had been smeared with gel preparation. The arm was then put into the mosquito cage [16].

In the mosquito repellent activity test, there are 2 groups to be tested; group 1 is the selected formula of cinnamon bark essential oil gel, which is applied to the right hand and the gel preparation without cinnamon bark essential oil (negative control) is applied to the left hand, group 2 is the product innovator as a positive control was applied to the right hand and the selected formula of cinnamon bark essential oil was applied to the left hand.

\section{Data analyses}

Organoleptic data, homogeneity, and $\mathrm{pH}$ were analyzed descriptively, while data on viscosity, spreadability, and adhesion were analyzed using one-way ANOVA with $95 \%$ confidence level. If the data obtained are significantly different, then proceed with the Tukey HSD test. The data of the anti-mosquito test was calculated using the formula for protection power according to the Guideline for Efficacy Testing of Mosquito Repellents for Human Skin from WHO, 2009 [16].

\section{RESULTS AND DISCUSSION}

The Cinnamon essential oil used in this study used is part of the bark. At the first, we conducted organoleptic identification includes shape, color, and smell. The results obtained in this process are presented in table 2 .

Table 2: Identification of Cinnamon bark essential oil

\begin{tabular}{llll}
\hline No. & Organoleptic & Observation & CoA specification \\
\hline 1. & Shape & Watery & Watery \\
2. & Colour & Dark Yellow & Dark Yellow \\
3. & Odor & Strong Scent & Strong Scent \\
\hline
\end{tabular}

The results obtained showed that the shape, color, and smell of Cinnamon bark essential oil indicated on the CoA in accordance with organoleptic observations. The second stage was the verification of the Cinnamon bark essential oil CoA. This verification stage is carried out by comparing the value listed on the CoA of cinnamon bark oil with the theoretical value i. e SNI (2006) [17]. Verification includes data on refractive index, density, solubility in alcohol, solubility in water, and cinnamaldehyde content. The results obtained from this process are showed in table 3.

Table 3: Verification of Cinnamon bark essential oil

\begin{tabular}{llll}
\hline No. & Parameter & Theoretical & CoA specification \\
\hline 1. & Refractive index & $1.008-1.030($ SNI, 2006) & 1.021 \\
2. & Density & $1.559-1.599($ SNI, 2006) & 1.598 \\
3. & Solubility in alcohol & Soluble (SNI, 2006) & Soluble \\
4. & Solubility in water & Insoluble (SNI, 2006) & Insoluble \\
5. & Cinnamaldehyde & $65-89 \%$ (Kardinan, 2007) & $86.73 \%$ \\
\hline
\end{tabular}

The results obtained indicate that the refractive index, density, solubility in alcohol, solubility in water, and the cinnamaldehyde content are in the range or according to the theoretical based on Indonesian National Standard (SNI, 2006) [17] and meet the specifications listed on CoA Lansida Group Yogyakarta.
The organoleptic observations of the gel preparations were conducted by observing the shape, color, and odor of the Cinnamon bark essential oil gel during storage for $4 \mathrm{w}$. Based on the results of the observations showed that all the gel formulas have a variety of viscosities, milky white color and a characteristic 
odor of cinnamon bark essential oil, which did not change shape, color, and odor during observation. The organoleptic observations of the Cinnamon bark essential oil gel could be seen in table 4 and table 5 .

Table 4: Organoleptic observation on dosage form changes

\begin{tabular}{lllll}
\hline Time (Days) & Dosage form & & & \\
\cline { 2 - 5 } & F1 & F2 & F3 & C (-) \\
\hline 1 & + & ++ & +++ & + \\
7 & + & ++ & ++ & + \\
14 & + & ++ & ++ & + \\
21 & + & ++ & +++ & + \\
28 & + & ++ & +++ & + \\
\hline
\end{tabular}

Table 5: Observation data on changes in the odor of the preparation

\begin{tabular}{llll}
\hline Time (Days) & Odor & F2 & F3 \\
\cline { 2 - 4 } & F1 & ++ & ++ \\
\hline 1 & +++ & ++ & ++ \\
7 & +++ & ++ & ++ \\
14 & +++ & ++ & ++ \\
21 & +++ & ++ & ++ \\
\hline
\end{tabular}

Annotation: +++: The aroma of essential oils is very sharp, ++ :The aroma of essential oils is sharp, +:The aroma of essential oils is less sharp

The various of viscosity can be influenced by variations in carbopol concentrations. The higher the concentration of carbopol, the thicker gel preparation produced. The color of gel preparation is milky white and not transparent like gel preparations commonly; this can occur due to the mixing of essential oils into the water, but according to Cosmetics Formulary, the color of the gel preparation does not have to be transparent, it is still allowed to be opaque [18]. The smell resulted from all formulas of the gel is a distinctive spicy smell of Cinnamon bark essential oil with the sharpest is in formula 1 than formulas 2 and 3.

The results of the homogeneity observations on the Cinnamon bark essential oil gel preparations demonstrated that all the formulas did not present coarse grains when the gels were smeared on a glass plate. This fact shows that all the gel preparations are homogenous. The resulting gel remains homogeneous during the storage period, it can be stated that the gel preparation is stable.

The results of measuring the $\mathrm{pH}$ of the Cinnamon bark essential oil gel preparation for $4 \mathrm{w}$ of storage showed that the preparation had a $\mathrm{pH}$ between 5.0-6.0. The $\mathrm{pH}$ value of the skin ranges from 4.5 to 6.5 [19]. This result displayed that $\mathrm{pH}$ of Formula 1 decrease at the $4^{\text {th }}$ week of storage. The $\mathrm{pH}$ of Formula 2 and Formula 3 decreased in the $2^{\text {nd }}$ to $4^{\text {th }}$ week of storage. The decreasing of $\mathrm{pH}$ is related to the length of storage, the longer the gel storage, the lower the $\mathrm{pH}$ of the gel preparation [20]. This condition can be caused by environmental influences such as light and oxygen in acidic contact with the essential oils as active compounds during storage thus, they will undergo an oxidation reaction with air catalyzed by light, will then increase the acid number and form an acidic compound, cause changes in odor and color [21].

The viscosity measurement of the gel preparation for $4 \mathrm{w}$ of storage was performed to determine the magnitude of the changes in viscosity and gel stability. Gel stability parameters can also be seen from the stability of the gel phase that occurs during storage. The viscosity of the gel preparations showed that the higher the concentration of carbopol, the viscosity of the gel preparation increased from 29,160 cp for Formula 1 contain 0.5 grams of carbopol to $>1,914,000 \mathrm{cp}$ for Formula 3 containing 2 grams of carbopol on the first day of manufacture. This increasing is due to the swelling property of the base itself and also because an increase in the amount of gelling agent used can strengthen the gel matrix, causing a viscosity increasing [22]. The graph of the results of the measurement of viscosity on storage for $4 \mathrm{w}$ can be seen in fig. 1 .

Based on the fig. 1, it was found that Formula 1 had the best and most stable viscosity during storage. We could see only Formula 1 has a viscosity within the range of good viscosity values, which is from 20,000-40,000 cps [23].

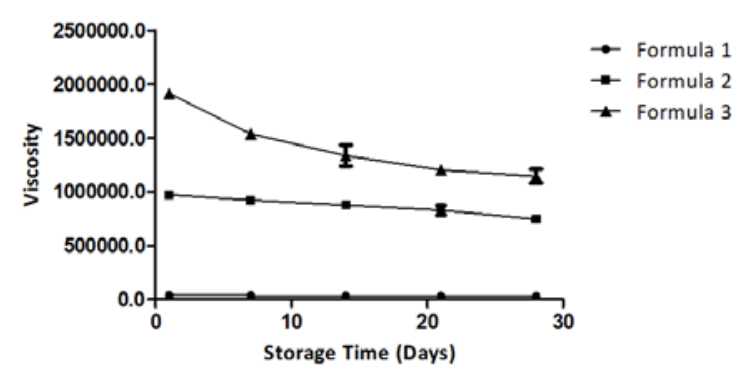

Fig. 1: Profile of relationship between storage time and viscosity, the value resulted from triplicate experiments

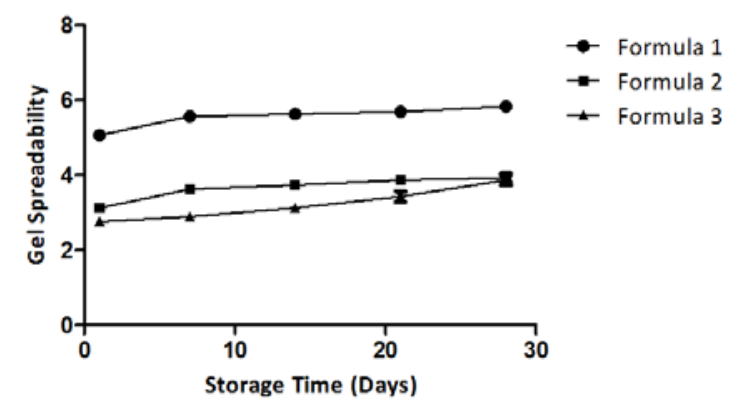

Fig. 2: Profile of relationship between storage time and gel spreadability, the value resulted from triplicate experiments

The gel spreadability test was performed to determine how much the gel's ability to spread on the skin was. One of the factors that affect the spreadability of the gel is the amount and strength of the gel matrix. The more and stronger the gel matrix, the lower the spreadability of the gel [24]. The results of the gel spreadability test displayed that Formula I and Formula II increased slightly since the $1^{\text {st }}$ week to the $4^{\text {th }}$ week of storage, Formula III increased significantly at the $2^{\text {nd }}$ to $4^{\text {th }}$ week of storage. Formula 1 , with the lower base concentration and lower viscosity as compared to Formula 2 and 3, had greater spreading. This shows an inverse 
relationship between spreadability and viscosity, the greater the viscosity of the preparation, the smaller the spreading. This is because a large viscosity requires greater pressure to flow with the same amount of pressure; the distribution of preparations with a larger viscosity will be smaller. The graph of the results of the measurement of the gel spreadability on storage for $4 \mathrm{w}$ can be seen in fig. 2.

According to the results of the spreadability test of the Cinnamon bark oil gel preparation, we conclude that the best formula is Formula 1 because only formula 1 is included in the range of good gel spreadability, which is between 5 to $7 \mathrm{~cm}$ [23]

Adhesion test was performed to determine the strength of the gel attached to the skin. The longer the gel is attached to the skin, the better the action of the drug at the site of action, but if it is attached to the skin for too long it will be difficult to remove and will interfere with the absorption of the drug into the skin [25]. Based on the measurement of gel adhesion, Formula 1 decreased slightly but remained stable. The adhesion of Formula 2 decreased since day 5 in the $1^{\text {st }}$ week to day 28 in the $3^{\text {rd }}$ week. The adhesion of Formula 3 decreased at the $1^{\text {st }}$ to $4^{\text {th }}$ week of storage. Formula 1 has the smallest adhesion; this shows a proportional relationship between the decrease in adhesion and the decrease in viscosity; the smaller the viscosity of the preparation, the smaller the adhesion. The graph of the results of the gel adhesion measurement on storage for $4 \mathrm{w}$ can be seen in fig. 3 .

Based on the gel adhesion test, we conclude that the Formula 1 is the best, which is more than 1 second [26]. Formula 1 is also the most stable formula at $4 \mathrm{w}$ of storage due to the relationship between viscosity and adhesion.

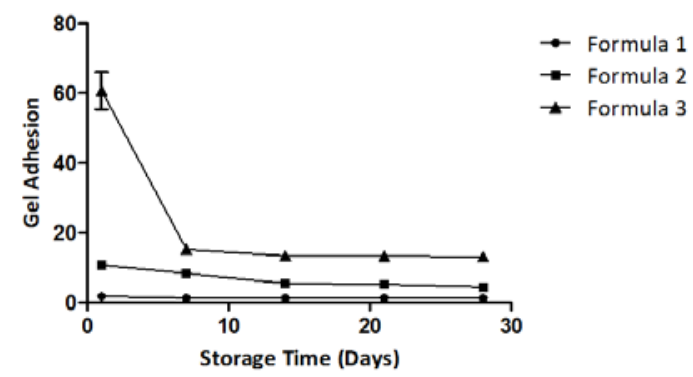

Fig. 3: Profile of relationship between storage time and gel adhesion, the value resulted from triplicate experiments

The results of the mosquito repellent activity of $1 \%$ Cinnamon bark essential oil gel at 0 to $6 \mathrm{~h}$ were $100 \%, 96.92 \%, 83.82 \%, 91.52 \%$, $92.98 \%, 91.18 \%$, and $76.81 \%$. These results indicate that the protective power of Cinnamon bark essential oil gel is still below the standard set by WHO where the anti-mosquito protection is effective if at least $90 \%$ for $6 \mathrm{~h}$ [16]. The results of the mosquito repellent activity test can be seen in table 7 .

Table 7: Results of Cinnamon bark oil gel protective power as compared to negative control

\begin{tabular}{|c|c|c|c|c|}
\hline \multirow[t]{2}{*}{ Treatment } & \multirow[t]{2}{*}{ Times (H) } & \multicolumn{2}{|c|}{ Average mosquito bite } & \multirow[t]{2}{*}{ Protective power (\%) } \\
\hline & & Control (-) & Sample & \\
\hline \multirow{7}{*}{$\begin{array}{l}\text { Cinammon bark essential } \\
\text { oil gel } 1 \%\end{array}$} & 0 & $6.7 \pm 1.64$ & 0 & 100 \\
\hline & 1 & $6.5 \pm 0.97$ & $0.2 \pm 0.42$ & 96.92 \\
\hline & 2 & $6.8 \pm 1.39$ & $1.1 \pm 0.74$ & 83.82 \\
\hline & 3 & $5.9 \pm 0.99$ & $0.5 \pm 0.71$ & 91.52 \\
\hline & 4 & $5.7 \pm 0.67$ & $0.4 \pm 0.69$ & 92.98 \\
\hline & 5 & $6.8 \pm 1.55$ & $0.6 \pm 0.52$ & 91.18 \\
\hline & 6 & $6.9 \pm 1.66$ & $1.6 \pm 1.5$ & 76.81 \\
\hline
\end{tabular}

$\mathrm{n}=10$, All values represent mean \pm SD.

The decrease in the protective power of the gel can be caused by the volatile property of the active ingredients of the gel which is at the $5^{\text {th }}$ and $6^{\text {th }}$ hours the amount of essential oil contained in the gel decreases. It can be stated that this Cinnamon bark essential oil gel is effective as a mosquito repellent for $4 \mathrm{~h}$. In addition to the active ingredient of the gel, there is many factors can reduce the protective power of the gel such as smearing technique, environment such as humidity and inner factor such as body temperature [27].

The results of the mosquito repellent activity test for Cinnamon bark essential oil gel preparations as compared to innovator products can be seen in table 8 .

Table 8: Results of Cinnamon bark oil gel protective power as compared to innovator product

\begin{tabular}{|c|c|c|c|c|}
\hline \multirow[t]{2}{*}{ Treatment } & \multirow[t]{2}{*}{ Times (H) } & \multicolumn{2}{|c|}{ Average mosquito bite } & \multirow[t]{2}{*}{ Sig $(p<0.05)$} \\
\hline & & Sample & Control (+) & \\
\hline \multirow[t]{7}{*}{ Innovator Product } & 0 & 0 & 0 & - \\
\hline & 1 & $0.3 \pm 0.48$ & $0.1 \pm 0.32$ & 0.267 \\
\hline & 2 & $0.6 \pm 0.69$ & $0.3 \pm 0.48$ & 0.313 \\
\hline & 3 & $0.4 \pm 0.69$ & $0.1 \pm 0.32$ & 0.255 \\
\hline & 4 & $0.3 \pm 0.67$ & $0.2 \pm 0.42$ & 0.914 \\
\hline & 5 & $1.0 \pm 1.05$ & $0.6 \pm 0.84$ & 0.368 \\
\hline & 6 & $1.5 \pm 1.65$ & $1.2 \pm 0.92$ & 0.691 \\
\hline
\end{tabular}

$\mathrm{n}=10$, All values represent mean \pm SD

In general, for $6 \mathrm{~h}$, the number of mosquitoes landed on the Cinnamon bark oil gel was more than the number of mosquitoes landed on the innovator's product. The difference in the data was then analyzed by the Mann-Whitney test and the significance since the $1^{\text {st }} \mathrm{h}$ to the $6^{\text {th }} \mathrm{h}$ respectively was $0.267 ; 0.313 ; 0.255 ; 0.914$; $0.368 ; 0.691(\mathrm{p}<0.05)$, which means the selected gel formula containing $1 \%$ cinnamon bark essential oil did not provide a significant difference in anti-mosquito protection as compared to the innovator product.
However, the development of gel preparation for repellent should be continued further to provide a pharmaceutical dosage form that comfort to use and is safe for humans and the environment. Currently, some herbs also tested the effectiveness for repellents such as Duranta plumieri [28] and Acalyphia indica [29].

\section{CONCLUSION}

Based on the results of the study, the gel preparation of Cinnamon bark essential oil has mosquito repellent activity. However, if the gel 
preparation will be applied to the community, it is necessary to test the irritation to human skin thus, the Cinnamon bark essential oil gel preparation can be well received. The innovator product has a greater protection power than the selected gel. The concentration of $1 \%$ Cinnamon bark essential oil is relatively smaller as compared to innovator products with $12.5 \%$ DEET content. Hence, it is necessary to do further research on the optimum concentration of Cinnamon bark essential oil as an anti-mosquito preparation.

The selected formula of Cinnamon bark essential oil gel is Formula 1. Formula 1 does not change shape; color; and odor, remained homogeneous during storage, had a pH value of 6 which was still within the skin $\mathrm{pH}$ range, had a viscosity value of $39,100-30,137 \mathrm{cp}$ the spreadability of $5.07-5.83 \mathrm{~cm}$, the adhesion of $1.33-1.86$ seconds. The selected formula of Cinnamon bark essential oil gel has activity as an effective mosquito repellent for $4 \mathrm{~h}$.

\section{ACKNOWLEDGMENT}

We thank Preggi Salveza and Inas Ghausani for helping with some experiments in the research.

\section{FUNDING}

The research was funded independently.

\section{AUTHORS CONTRIBUTIONS}

All authors have contributed equally.

\section{CONFLICTS OF INTERESTS}

There is no conflict of interest among the authors.

\section{REFERENCES}

1. Von Rintelen K, Arida E, Hauser C, von Rintelen K, Arida E, Hauser C, von Rintelen K, Arida E, Hauser C, von Rintelen K, Arida E, Hauser C. A review of biodiversity-related issues and challenges in megadiverse Indonesia and other Southeast Asian countries. Res Ideas Outcomes. 2017;3:e20807. doi: 10.3897/rio.3.e20860.

2. Wijayanti SPM, Sunaryo S, Suprihatin S, McFarlane M, Rainey SM, Dietrich I, Schnettler E, Biek R, Kohl A. Dengue in Java, Indonesia: relevance of mosquito indices as risk predictors. PLOS Negl Trop Dis. 2016;10(3):e0004500. doi: 10.1371/journal.pntd.0004500, PMID 26967524.

3. Norris EJ, Coats JR. Current and future repellent technologies: the potential of spatial repellents and their place in mosquitoborne disease control. Int J Environ Res Public Health. 2017;14(2). doi: 10.3390/ijerph14020124, PMID 28146066.

4. Grant GG, Estrera RR, Pathak N, Hall CD, Tsikolia M, Linthicum KJ, Bernier UR, Hall AC. Interactions of DEET and novel repellents with mosquito odorant receptors. J Med Entomol. 2020;57(4):1032-40. doi: 10.1093/jme/tjaa010, PMID 32048720.

5. Paluch G, Bartholomay L, Coats J. Mosquito repellents: a review of chemical structure diversity and olfaction. Pest Manag Sci. 2010;66(9):925-35. doi: 10.1002/ps.1974, PMID 20623705.

6. Koren G, Matsui D, Bailey B. DEET-based insect repellents: safety implications for children and pregnant and lactating women. CMAJ. 2003;169(3):209-12. PMID 12900480.

7. Kasim NN, Ismail NASS, Masdar ND, Hamid FA, Nawawi WI. Extraction and potential of cinnamon essential oil towards repellency and insecticidal activity. Int J Sci Res Publ. 2014;4(7):2250-3153.

8. Balijepalli MK, Buru AS, Sakirolla R, Pichika MR. Cinnamomum genus: a review on its biological activities. Int J Pharm Pharm Sci. 2017;9(2):1-11.

9. Mdoe FP, Cheng SS, Msangi S, Nkwengulila G, Chang ST, Kweka EJ. Activity of Cinnamomum osmophloeum leaf essential oil against anopheles gambiae s. s. Parasit Vectors. 2014;7(1):209. doi: 10.1186/1756-3305-7-209, PMID 24885613.

10. Fouad HA. Bioactivity of essential oils of medicinal plants against Bruchidius incarnatus (Bohemann, 1833). Agric Environ Manag. 2013;2(6):135-41.

11. Pohlit AM, Lopes NP, Gama RA, Tadei WP, Neto VF. Patent literature on mosquito repellent inventions which contain plant essential oils-a review. Planta Med. 2011;77(6):598-617. doi: 10.1055/s-0030-1270723, PMID 21328177.

12. Kaur M, Nagpal M, Singh M, Singh TG, Aggarwal G, Dhingra GA. Improved antibacterial activity of topical gel-based on nanosponge carrier of cinnamon oil. Biolmpacts. 2021;11(1):23-31. doi: 10.34172/bi.2021.04, PMID 33469505.

13. Verma A, Singh S, Kaur R, Jain UK. Topical gels as drug delivery systems: a review. Int J Pharm Sci Rev Res. 2013;23(2):374-82.

14. Dantas MG, Reis SA, Damasceno CM, Rolim LA, Rolim-Neto PJ, Carvalho FO, Quintans-Junior LJ, Almeida JR. Development and evaluation of stability of a gel formulation containing the monoterpene borneol. Scientific World Journal. 2016;2016:7394685. doi: 10.1155/2016/7394685. PMID 27247965.

15. Bairagi GR, Patel VP. Formulation and development of curcumin based emulgel in treatment and recurrence of vaginal candidiasis. Int J Curr Pharm Sci. 2021;13(5):89-99. doi: 10.22159/ijcpr.2021v13i5.1900.

16. Who. Guidelines for efficacy testing of mosquito repellents for human skin. Who/HTM/Ntd/Whopes/20094; 2009. p. 1-6.

17. Minyak Kulit SNI, Manis K; 2006.

18. Chemicals SP. Cosmet Formul; 2017. p. 1-31.

19. Ali SM, Yosipovitch G. Skin pH: from basic science to basic skincare. Acta Derm Venereol. 2013;93(3):261-7. doi: 10.2340/00015555-1531, PMID 23322028.

20. Chaerunisaa AY, Mita SR, Rahmat DD. Formulation and stability evaluation of atenolol gel in two different bases. Asian J Pharm Clin Res. 2019;12(3):383-6. doi: 10.22159/ajpcr.2019.v12i3.30727.

21. Gu X, Sang H, Pu C, Zhang L, Zhao Q. Effect of $\mathrm{pH}$ on gelling performance and stability of HPAM/Cr3+weak gel. Ifeesm; 2015. p. 401-4.

22. Maxey J. AADE-11-NTCE-23 viscosity and gel structure: the unseen results of their manipulation; 2011.

23. Abdul Rahman MN, Qader OAJA, Sukmasari S, Ismail AF Doolaanea AA. Rheological characterization of different gelling polymers for dental gel formulation. J Pharm Sci Res. 2017;9(12):2633-40.

24. Shukr MH, Metwally GF. Evaluation of topical gel bases formulated with various essential oils for antibacterial activity against methicillin-resistant staphylococcus aureus. Trop J Pharm Res. 2013;12(6):877-84. doi: 10.4314/tjpr.v12i6.3.

25. Ruela ALM, Perissinato AG, Lino MEdS, Mudrik PS, Pereira GR. Evaluation of skin absorption of drugs from topical and transdermal formulations. Braz J Pharm Sci. 2016;52(3):52744. doi: $10.1590 /$ s1984-82502016000300018.

26. B SA, Jeganath S, Jeevitha E. Pharmaceutical gels and recent trends- A review. Res J Pharm Technol. 2019;12(12):6181-6. doi: 10.5958/0974-360X.2019.01073.4.

27. Gagliardo A, Pollonara E, Vanni L, Giunchi D. An experimental study on the effectiveness of a gel repellent on feral pigeons. Eur J Wildl Res. 2020;66(2). doi: 10.1007/s10344-020-1365-4.

28. Payal Mittal, Manish Goswami, Monika Airi. Mosquito repellent action of Duranta plumieri (Verbenaceae) against Culex quinquefasciatus. Asian J Pharm Clin Res. 2019;12(6):317-20. doi: 10.22159/ajpcr.2019.v12i6.32981.

29. UA, GT, PT, SA. Pupal emergence inhibition activity of acalypha indica leaf extract against dengue vector, aedes albopictus mosquito. Int J Pharm Pharm Sci. 2017;9(8):114. doi: 10.22159/ijpps.2017v9i8.19362. 